\title{
Relationship of ventilatory inefficiency and low cardiorespiratory fitness in the elderly: a retrospective observational study
}

Murillo Frazãol (D) Luciana Margarida de Santana Madruga França ${ }^{2}$ (DD Samarony Caio Moreno Bezerra ${ }^{3}$ (D) Paulo Eugênio Silva ${ }^{4}$ (D)

\section{Abstract}

Objectives: To check if ventilatory inefficiency is related to low cardiorespiratory fitness in the elderly and to identify the variable(s) of the cardiopulmonary exercise test (CPET) best suited to determining this relationship. Methods: A retrospective analysis of 1357 CPETs was performed. Sixty-one subjects over 60 years old with a ventilatory efficiency slope $\left(\mathrm{VE} / \mathrm{VCO}_{2}\right)$ index $>35$ were selected and divided into two groups: low cardiorespiratory fitness (VO2 $<80 \%$ predicted) $(n=22)$ and normal cardiorespiratory fitness (VO2 $>80 \%$ predicted) $(\mathrm{n}=39)$ and were compared with a control group of healthy elderly persons with normal cardiorespiratory fitness and $\mathrm{VE} / \mathrm{VCO}_{2}$ slope index $<35(\mathrm{n}=16)$, matched by gender, weight, height, and age. Results: Oxygen consumption had a low correlation with $\mathrm{VE} / \mathrm{VCO}_{2}$ slope $(\mathrm{r}=-0.35, p<0.01)$, a moderate correlation with the cardiorespiratory optimal point $(\mathrm{COP})(\mathrm{r}=-0.59, p<0.001)$ and a strong correlation with oxygen uptake efficiency Slope $(\mathrm{OUES})=0.92, p<0.0001)$. In relation to the ROC curve, the VE/VCO slope presented an area under the curve of 0.65 , but without statistical significance $(p>$ $0.05)$; the COP showed an area under the curve of $0.84(p<0.0001)$ and the OUES presented an area under the curve of $0.81(p<0.0001)$. Conclusion: Ventilatory inefficiency is related to poor cardiorespiratory fitness in the elderly. The COP and OUES were more accurate at predicting low cardiorespiratory fitness.

\footnotetext{
Universidade Federal da Paraíba, Laboratório de Exercício e Treinamento Físico Aplicado à Saúde. João Pessoa, PB, Brasil.

2 Marinha do Brasil, Hospital Central da Marinha. Rio de Janeiro, RJ, Brasil.

Hospital Lar, Departamento de Fisioterapia. João Pessoa, PB, Brasil.

4 Universidade de Brasília, Programa de Doutorado em Ciências e Tecnologias em Saúde. Brasília, DF, Brasil.
}

The authors declare there are no conflicts of interest in relation to the present study.

No funding was received in relation to the present study.

Correspondence

Keywords: Efficiency. Pulmonary Ventilation. Ventilation-Perfusion Ratio. Cardiorespiratory Fitness.

Exercise Test. 


\section{INTRODUCTION}

With senility, the respiratory system undergoes anatomical and physiological changes that directly impact the ventilation/pulmonary perfusion relationship. The pulmonary parenchyma loses its structural support ${ }^{1}$. Changes in the connective tissue increase chest stiffness and reduce the elastic component of the lungs, directly influencing respiratory mechanics ${ }^{2}$. There is also an increase in physiological dead space, which promotes an increase in "ventilatory waste".

Ventilatory inefficiency arises when the parts of the respiratory system responsible for gas exchange do not function properly ${ }^{3}$. This malfunction can be caused either by changes in pulmonary circulation (perfusion disorders) or by changes in the airways and alveoli (ventilation disorders), alone or in combination, causing a failure in the ventilation/ perfusion ratio.

The integrated assessment of cardiorespiratory responses during exercise provides important information on ventilatory efficiency ${ }^{4}$. The Cardiopulmonary Exercise Test (CPET) enables this analysis and provides several variables ${ }^{5}$. Classically the most used variable for analysis of ventilatory efficiency is the variation of ventilation through changes in carbon dioxide production $\left(\mathrm{VE} / \mathrm{VCO}_{2}\right.$ slope $)^{6}$, which can be considered the gold standard for this type of assessment in pathological situations? Other variables are used for this analysis, such as the variation in oxygen consumption efficiency Oxygen Uptake Efficiency Slope (OUES) $)^{7,8}$ and the Cardiorespiratory Optimal Point $(\mathrm{COP})^{10}$ (a better ventilation/oxygen consumption relationship), and are also highly relevant.

Currently, cardiorespiratory fitness is considered a vital sign ${ }^{11}$ and, in pathological models, ventilatory inefficiency is related to low values of cardiorespiratory fitness (oxygen consumption) ${ }^{12}$. With advancing age, a physiological reduction of maximal oxygen consumption is expected, but relatively common pathological situations in the elderly (chronic obstructive pulmonary disease and heart failure) promote a greater reduction of oxygen consumption $^{13,14}$.
Due to the physiological changes of the aging process in the respiratory system, this study aimed to verify if ventilatory inefficiency is related to poor cardiorespiratory fitness in the elderly. The secondary objective was to identify which CPET variables were most effective at determining this relationship.

\section{METHODS}

A cross-sectional study based on a retrospective analysis of 1357 CPETs was carried out. All CPETs were performed by a single examiner with expertise in the examination. The analysis was performed using data obtained from a cardiopulmonary assessment clinic from April 2012 to August 2016.

Therefore, exams that met the following inclusion criteria were selected: age over 60 years; $\mathrm{VE} / \mathrm{VCO}_{2}$ slope $>35$ and absence of locomotor limitations that hindered the test. The VE/ $\mathrm{VCO}_{2}$ slope variable was used for screening of the elderly as it is a gold standard measure of ventilatory efficiency. Examinations of people who presented any report of locomotor limitation were excluded from the analysis.

Sixty-one elderly individuals were divided into two groups: low cardiorespiratory fitness $\left(\mathrm{VO}_{2}<80 \%\right.$ of predicted $)^{15}(\mathrm{n}=22)$ and normal cardiorespiratory fitness $\left(\mathrm{VO}_{2}>80 \%\right.$ of predicted) $(\mathrm{n}=39)$ and were compared with a group of healthy elderly persons with normal cardiorespiratory fitness and VE/ $\mathrm{VCO}_{2}$ slope $<35$ ( $\left.\mathrm{n}=16\right)$, matched for gender, weight, height and age. The elderly selected were asked about their history (self-reported) of cardiopulmonary diseases (eg: chronic obstructive pulmonary disease, pulmonary fibrosis, heart failure, pulmonary hypertension...) and underwent an anthropometric assessment followed by the Cardiopulmonary Exercise Test.

The technical procedures followed the guidelines of the American Thoracic Society/American College of Chest Physicians ${ }^{16}$ for cycle ergometer testing. The examinations were performed on an electromagnetic braking cycle ergometer (Inbrasport CG-04 model; INBRAMED, Porto Alegre, Brazil). Each individual performed a ramp protocol up to the maximum tolerance limit, starting with 
no load and with an individually selected load increment rate $(5-20 \mathrm{~W} / \mathrm{min})$. Subjects were strongly encouraged to reach their maximum effort through verbal stimuli. For gas analysis a VO2000 model analyzer (MedGraphics, St. Paul, USA) was used, calibrated before each examination according to the manufacturer's instructions. Data were collected through the (ErgoMet 13 model software (HW, Belo Horizonte, Brazil).

The reports of cardiopulmonary diseases was recorded in absolute and percentage values. Through the CPET data, the following variables were analyzed: respiratory workload (RW), oxygen consumption $\left(\mathrm{VO}_{2}\right)$, maximum ventilation $(\mathrm{VE})$, oxygen pulse $\left(\mathrm{PuO}_{2}\right)$, heart rate $(\mathrm{HR})$, ventilatory oxygen and carbon dioxide equivalents $\left(\mathrm{VE} / \mathrm{VO}_{2}\right.$ and $\mathrm{VE} / \mathrm{VCO}_{2}$ ), ventilatory efficiency index (VE/ $\mathrm{VCO}_{2}$ slope), cardiorespiratory optimal point (COP) and oxygen uptake efficiency slope (OUES). Data were collected every 10 seconds of the ramp protocol. After collection, the data were adjusted by a filter (mean of seven points) to avoid noise.

The normality and homogeneity of the sample were analyzed by the Shapiro-Wilk and Levene tests, respectively. To evaluate the differences between the measures, one-way ANOVA with Tukey post hoc was used. Inter and intra group differences were analyzed by two-way ANOVA with Tukey post hoc. The correlation of variables was tested using Pearson and Spearman correlations. The sensitivity and specificity of the variables for determining low cardiorespiratory fitness were observed by receiver operating characteristic (ROC) curve analysis. Statistical significance was accepted with a value of $p<0.05$.

The study complied with the norms of National Health Council resolution 466/12, and was submitted to an ethics research committee under opinion number 2.319.091.

\section{RESULTS}

The elderly evaluated had a mean age of $68 \pm 6$ years. A total of $95 \%$ (21 of 22 ) of the elderly in the low cardiorespiratory fitness group and 8\% (three of 39) of those in the normal cardiorespiratory fitness group reported the presence of cardiopulmonary disease. The matching variables: age, weight, height, body mass index and sex presented similar values in relation to the three groups $(p>0.05)$ (Table 1$)$. The group with low cardiorespiratory fitness presented lower values of oxygen consumption, oxygen pulse and workload $(p<0.01)$. The normal cardiorespiratory fitness group had a higher maximum ventilation than the other groups $(p<0.01)$. Heart rate at peak exercise did not differ in the three groups $(p>0.05)$ (Table 2).

Table 1. Anthropometric characteristics of individuals studied (N=77). João Pessoa, Paraíba, 2016.

\begin{tabular}{lllll}
\hline & $\begin{array}{l}\text { Low Fitness } \\
(\mathrm{n}=22) \\
\text { Mean } \pm \mathrm{sd}\end{array}$ & $\begin{array}{l}\text { Normal Fitness } \\
(\mathrm{n}=39) \\
\text { Mean } \pm \mathrm{sd}\end{array}$ & $\begin{array}{l}\text { Control } \\
(\mathrm{n}=16) \\
\text { Mean } \pm \mathrm{sd}\end{array}$ & $p$ value \\
\hline Age (years) & $71 \pm 7$ & $68 \pm 5$ & $68 \pm 6$ & $>0.05$ \\
\hline Weight $(\mathrm{kg})$ & $74 \pm 17$ & $70 \pm 13$ & $68 \pm 9$ & $>0.05$ \\
\hline Height $(\mathrm{cm})$ & $161 \pm 7$ & $161 \pm 8$ & $162 \pm 7$ & $>0.05$ \\
\hline BMI & $28 \pm 6$ & $27 \pm 5$ & $26 \pm 2$ & $>0.05$ \\
\hline Sex $(\mathrm{M} / \mathrm{F})$ & $12(51 \%) / 10(49 \%)$ & $19(48 \%) / 20(52 \%)$ & $7(49 \%) / 9(51 \%)$ & - \\
\hline
\end{tabular}

BMI: body mass index. $p>0.05$ intergroup comparison. ANOVA one-way with Tukey post hoc. 
Table 2. Basic exercise data. João Pessoa, Paraíba, 2016.

\begin{tabular}{lllll}
\hline & $\begin{array}{l}\text { Low Fitness } \\
(\mathrm{n}=22) \\
\text { Mean } \pm \mathrm{sd}\end{array}$ & $\begin{array}{l}\text { Normal Fitness } \\
(\mathrm{n}=39) \\
\text { Mean } \pm \mathrm{sd}\end{array}$ & $\begin{array}{l}\text { Control } \\
(\mathrm{n}=16) \\
\text { Mean } \pm \mathrm{sd}\end{array}$ & $p$ value \\
\hline Oxygen consumption (L/min) & $0.86 \pm 0.3^{\mathrm{a}}$ & $1.36 \pm 0.4$ & $1.39 \pm 0.3$ & $<0.01$ \\
\hline Oxygen consumption (\% pred) & $59 \pm 10^{\mathrm{a}}$ & $101 \pm 15$ & $101 \pm 11$ & $<0.01$ \\
\hline Oxygen pulse (mL/sis/min) & $6 \pm 2^{\mathrm{a}}$ & $10 \pm 2$ & $10 \pm 2$ & $<0.01$ \\
\hline Oxygen pulse (\% pred) & $64 \pm 9^{\mathrm{a}}$ & $110 \pm 18$ & $107 \pm 16$ & $<0.01$ \\
\hline Maximum ventilation (L/min) & $39 \pm 13$ & $53 \pm 17^{\mathrm{b}}$ & $44 \pm 10$ & $<0.01$ \\
\hline Workload (w) & $75 \pm 37^{\mathrm{a}}$ & $115 \pm 47$ & $113 \pm 37$ & $<0.01$ \\
\hline HR peak effort (b/min) & $134 \pm 17$ & $137 \pm 14$ & $140 \pm 13$ & $>0.05$ \\
\hline
\end{tabular}

HR: heart rate; ${ }^{a} p<0.01$ compared to normal fitness group and control; ${ }^{b} p<0.01$ compared to the low fitness and control group; $p>0.05$ intergroup comparison; ANOVA one-way with Tukey post hoc.

As shown in Figure 1, the groups showed varying behaviors regarding the ventilatory efficiency variables. The elderly with low cardiorespiratory fitness did not have different $\mathrm{VE} / \mathrm{VCO}_{2}$ slope values from the elderly with normal cardiorespiratory fitness $(p>0.05)$. Both presented values above those observed in the control group $(p<0.0001)$. The elderly with low cardiorespiratory fitness had higher COP values than the elderly with normal cardiorespiratory fitness and the control group $(p<0.0001)$. There were differences between the COP of the group with normal cardiorespiratory fitness and the control group $(p<0.01)$. In relation to OUES, the elderly with low cardiorespiratory fitness presented significantly lower values than the elderly with normal cardiorespiratory fitness and the control group $(p<0.0001)$. There were no differences between those with normal cardiorespiratory fitness and the control group $(p>0.05)$.
Regarding ventilatory oxygen equivalents, the elderly with low cardiorespiratory fitness presented higher values than those seen in the elderly with normal cardiorespiratory fitness and in the control group at all workloads $(p<0.0001)$. The elderly with normal fitness presented higher values than the control group at $25 \%, 50 \%, 75 \%$ and $100 \%$ of the workload (Figure 2). Regarding the ventilatory equivalents of carbon dioxide, the elderly with low cardiorespiratory fitness presented higher values than those seen in the elderly with normal cardiorespiratory fitness and in the control group at $0 \%, 25 \%$ and $50 \%$ of workload $(p<0.0001)$. At $75 \%$ and $100 \%$ of the workload there were no differences compared to the group with normal cardiorespiratory fitness $(p>0.05)$. The elderly with normal cardiorespiratory fitness presented values above the control group at $25 \%, 50 \%, 75 \%$ and $100 \%$ of the workload (Figure 2).

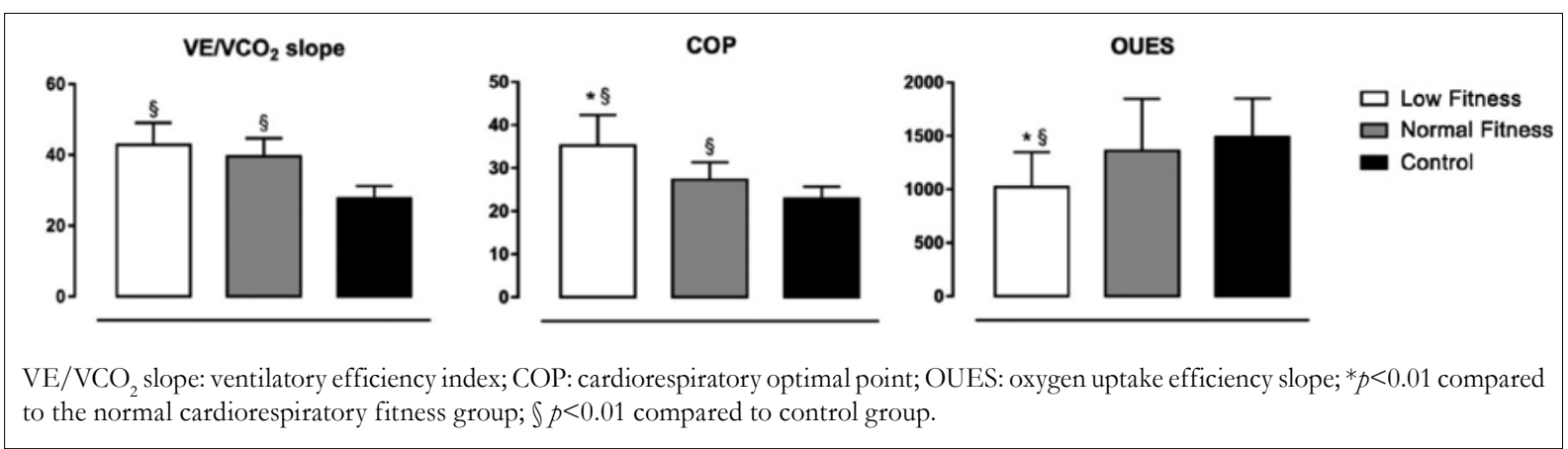

Figure 1. Behavior of ventilatory efficiency variables. 


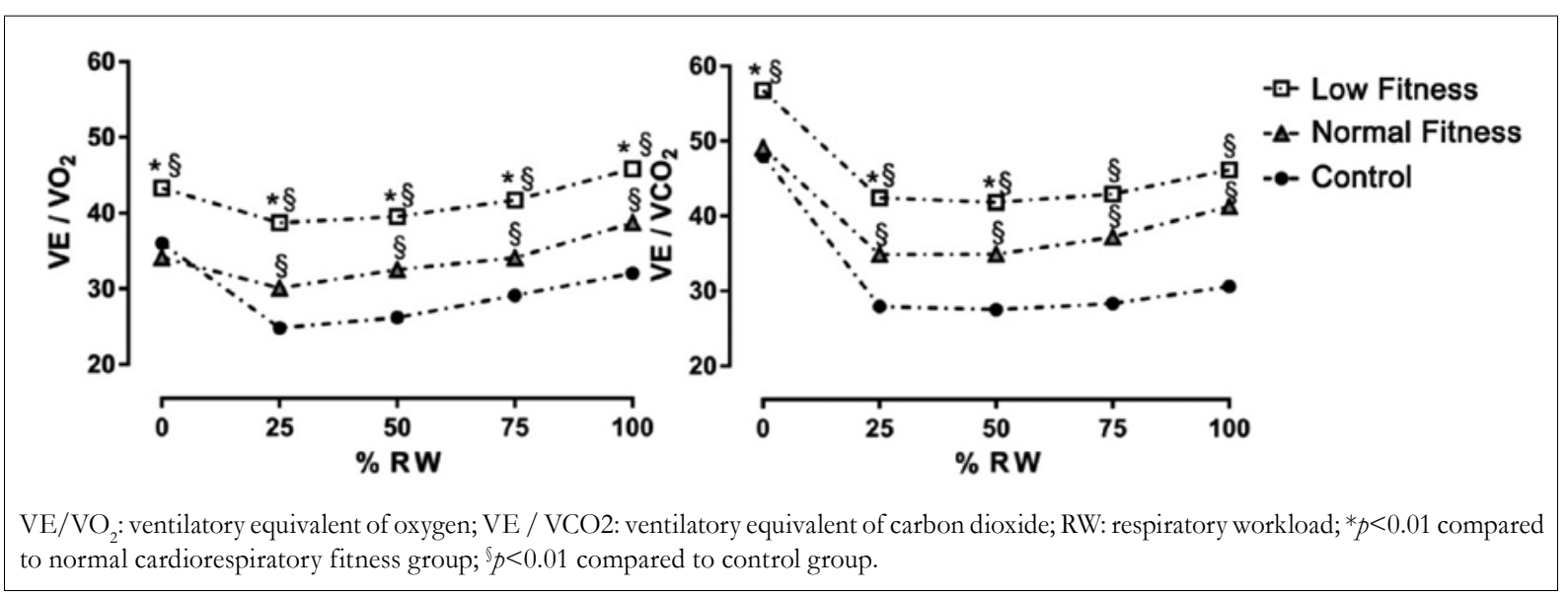

Figure 2. Oxygen and carbon dioxide ventilatory equivalents.

Oxygen consumption had a low correlation with $\mathrm{VE} / \mathrm{VCO}_{2}$ slope, a moderate correlation with COP and a strong correlation with OUES (Figure 3). Regarding the ROC curve to predict low cardiorespiratory fitness, the $\mathrm{VE} / \mathrm{VCO}_{2}$ slope presented an area under the curve with no statistical significance. $(p>0.05)$. The COP presented an area under the curve of 0.84 ( $p<0.0001$ ), with a value of 31 as the best point for sensitivity and specificity. The OUES presented an area under the curve of 0.81 $(p<0.0001)$ with a value of 1224 as the best point of sensitivity and specificity (Figure 4).

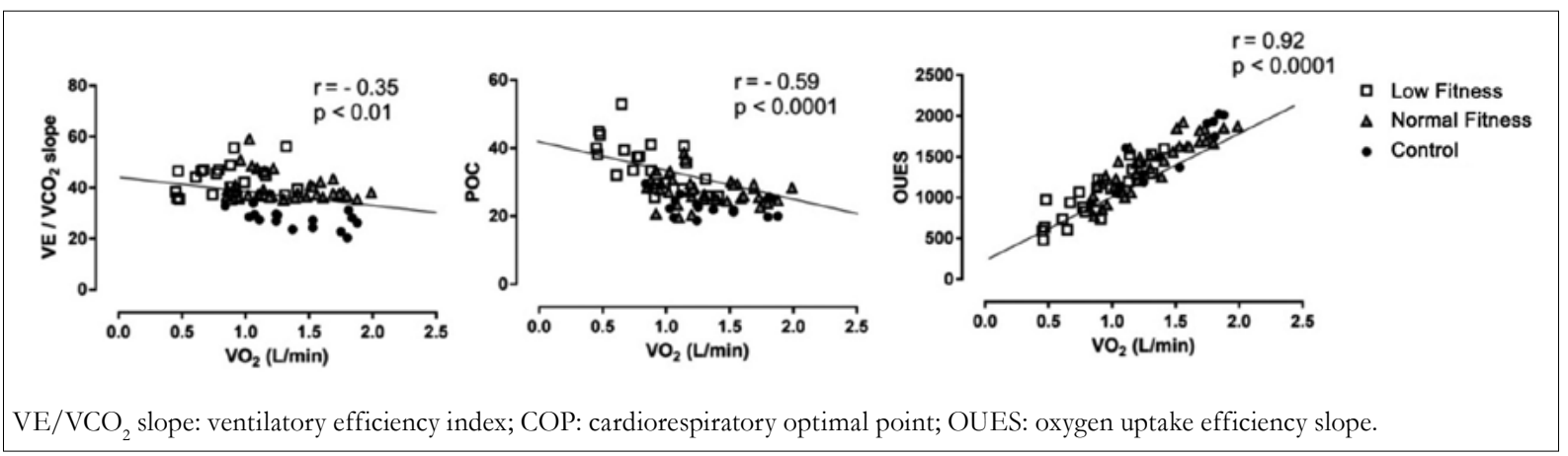

Figure 3. Correlation between ventilatory efficiency variables and $\mathrm{VO}_{2}$.
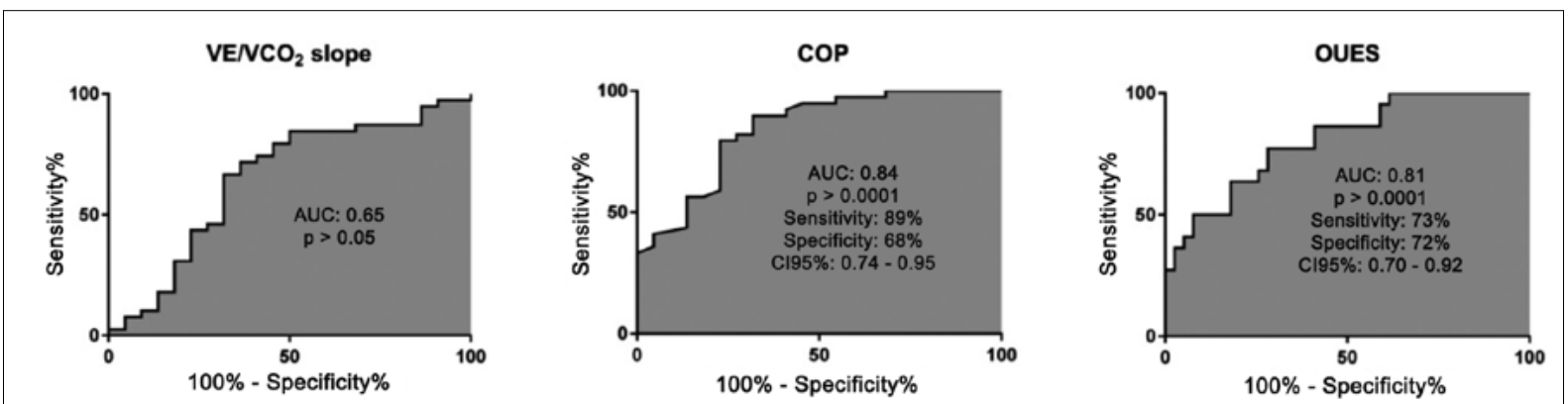

VE/VCO2 slope: ventilatory efficiency index; COP: cardiorespiratory optimal point; OUES: oxygen uptake efficiency slope.; AUC: area under the curve. CI: confidence interval

Figure 4. Accuracy of ventilatory efficiency variables in predicting low cardiorespiratory fitness. 


\section{DISCUSSION}

The present study demonstrated that VE/ $\mathrm{VCO}_{2}$ slope is not necessarily associated with poor cardiorespiratory fitness in the elderly, but that increased COP and reduced OUES are associated with poor cardiorespiratory fitness in this population. These ventilatory efficiency variables, COP and OUES, demonstrated higher sensitivity and specificity for the prediction of low cardiorespiratory fitness in the elderly.

Ventilatory inefficiency is generally associated with unfavorable clinical outcomes (increased morbidity and mortality). Traditionally, the VE/ $\mathrm{VCO}_{2}$ slope variable is the most commonly used for this analysis. In pathological models, elevated VE/ $\mathrm{VCO}_{2}$ slope is related to pulmonary hypertension ${ }^{18}$, low cardiorespiratory fitness ${ }^{13,19}$ and increased mortality ${ }^{20,21}$

Despite this, the presence of elevated VE/ $\mathrm{VCO}_{2}$ slope with normal cardiorespiratory fitness has been reported. Guazzi et al. ${ }^{17}$ analyzed 100 heart failure patients and found no correlation between elevated $\mathrm{VE} / \mathrm{VCO}_{2}$ slope and $\mathrm{VO}_{2}$. Thirty-five percent of the patients analyzed had normal cardiorespiratory fitness, which corroborates the findings of this research. In the elderly evaluated in this study, the $\mathrm{VE} / \mathrm{VCO}_{2}$ slope was also unable to predict low cardiorespiratory fitness.

Typical ventilatory equivalent behavior describes a parabola-shaped graph ${ }^{22}$. The smaller this parabola, the worse the ventilatory efficiency. In this study, the elderly with the lowest parabola were those with low cardiorespiratory fitness.

In theory, the moment in which COP occurs (lower $\mathrm{VE} / \mathrm{VO}_{2}$ value) corresponds to the best ventilation/perfusion ratio, i.e., it represents the maximum integration between the respiratory and cardiovascular systems ${ }^{10}$. COP is practically detected and occurs at relatively low exertion intensities (30$50 \% \mathrm{VO}_{2}$ peak). High COP values indicate ventilatory inefficiency, as there is increased ventilation for the consumption of one liter of oxygen. In the elderly persons evaluated in the present study, a correlation was observed between ventilatory inefficiency, due to increased COP, and low cardiorespiratory fitness. In addition, COP exhibited good sensitivity and specificity for the prediction of low cardiorespiratory fitness. In a retrospective study with 3331 CPETs, including healthy and chronically ill individuals, Ramos and Araújo ${ }^{23}$ also showed that subjects with high COP values had lower cardiorespiratory fitness and higher mortality.

Like COP, OUES does not require maximum effort to be determined. It reflects the relationship between oxygen uptake and total ventilation during incremental exercise and is well described by a single exponential function. Logarithmic regression is linear in almost all individuals, so it does not require maximum effort to be estimated ${ }^{7}$. OUES has excellent test/retest reliability and can serve as a complementary or alternative measure of cardiorespiratory fitness ${ }^{24}$. This is particularly important for individuals who have difficulty performing maximal effort, such as the elderly. Recently, Dougherty et al..$^{25}$ determined the effective accuracy of OUES for the prediction of cardiorespiratory fitness in this specific population, which is in line with the data presented in this research.

The present study had some limitations. A limiting factor was the absence of data on pulmonary artery pressure in the elderly, which is a variable directly related to markers of ventilatory efficiency. Other limiting factors were inherent to the retrospective analysis itself, such as the sample quantity (limited to exams already performed and which cannot be increased).

\section{CONCLUSION}

Ventilatory inefficiency is only related to poor cardiorespiratory fitness in the elderly when measured by the cardiorespiratory optimal point (COP) and oxygen uptake efficiency slope (OUES). These variables were more accurate for predicting such low cardiorespiratory fitness. Because they are submaximal measurements, they are excellent markers of cardiorespiratory fitness for the elderly, a population that often has limitations in performing the maximal exercise test.

Edited by: Ana Carolina Lima Cavaletti 


\section{REFERENCES}

1. Sicard D, Haak AJ, Choi KM, Craig AR, Fredenburgh LE, Tschumperlin DJ. Aging and anatomical variations in lung tissue stiffness. Am J Physiol Lung Cell Mol Physiol. 2018;314(6):946-55.

2. Pascotini FS, Fedosse E, Ramos MC, Ribeiro VV, Trevisan ME. Força muscular respiratória, função pulmonar e expansibilidade toracoabdominal em idosos e sua relação com o estado nutricional. Fisioter Pesqui. 2016;23(4):416-22.

3. Petersson J, Glenny RW. Gas exchange and ventilation - perfusion relationships in the lung. Eur Respir J. 2014;44:1023-41.

4. Ramos PS, Araújo CGS. Análise da estabilidade de uma variável submáxima em teste cardiopulmonar de exercício: ponto ótimo cardiorrespiratório. Eur Respir J. 2013;18(5):585-93.

5. Neder JA, Berton DC, Müller PT, Elbehairy AF, Rocha A, Palange P, et al. Canadian Respiratory Research Network. Ventilatory inefficiency and exertional dyspnea in early chronic obstructive pulmonary disease. Ann Am Thorac Soc. 2017;14(Suppl. 1):22-9.

6. Weatherald J, Farina S, Bruno N, Laveneziana P. Cardiopulmonary Exercise Testing in Pulmonary Hypertension. Ann Am Thorac Soc. 2017;14 (Suppl 1):84-92.

7. Hollenberg M, Tager IB. Oxygen uptake efficiency Slope: an index of exercise performance and cardiopulmonary reserve requiring only submaximal exercise. J Am Coll Cardiol. 2000;36(1):195-201.

8. Baba R, Nagashima M, Goto M, Nagano Y, Yokota $\mathrm{M}$, Tauchi N, et al. Oxygen uptake efficiency Slope: a new index of cardiorespiratory, funtitonal reserve derived from the relation between oxygen uptake and minute ventilation during incremental exercise. J Am Cad Cardiol. 1996;28(6):1567-72.

9. Guazzi M, Adams V, Conraads V, Halle M, Mezzani A, Vanhees L, et al. Clinical recommendations for cardiopulmonary exercise testing data assessment in specific patient populations. Circulation. 2012;126:2261-74

10. Ramos PS, Ricardo DR, Araujo CG. Cardiorespiratory optimal point: a submaximal variable of the cardiopulmonary exercise testing. Arq Bras Cardiol. 2012;99(5):988-96.

11. Ross R, Blair SN, Arena R, Church TS, Després $\mathrm{JP}$, Franklin BA, et al. Importance of assessing cardiorespiratory fitness in clinical practice: a case for fitness as a clinical vital sign. Circulation. 2016;134(24):653-99.
12. Teopompi E, Tzani P, Aiello M, Ramponi S, Visca D, Gioia MR, et al. Ventilatory response to carbon dioxide output in subjects with congestive heart failure and in patients with COPD with comparable exercise capacity. Respir Care. 2014;59(7):1157-9.

13. Frazão M, Silva PE, Frazão W, da Silva VZM, Correia Jr MAV, Gomes Neto M. Dynamic hyperinflation impairs cardiac performance during exercise in COPD. J Cardiopulm Rehabil Prev. 2019;39(3):187-92.

14. Clark AL, Davies LC, Francis DP, Coats AJS. Ventilatory capacity and exercise tolerance in patients with chronic stable heart failure. Eur J Heart Fail. 2000;2:47-51.

15. Neder JA, Nery LE, Castelo A, Andreoni S, Lerario MC, Sachs A, et al. Prediction of metabolic and cardiopulmonary responses to maximum cycle ergometry: a randomised study. Eur Respir J. 1999;14(6):1304-13.

16. Mezzani A. Cardiopulmonary Exercise Testing: basics of methodology and measurements. Ann Am Thorac Soc. 2017;14:3-11.

17. Guazzi M, de Vita S, Cardano P, Barlera S, Guazzi MD. Normalization for peak oxygen uptake increases the prognostic power of the ventilatory response to exercise in patients with chronic heart failure. Am Heart J. 2003;146(3):542-8.

18. Klaassen SHC, Liu LCY, Hummel YM, Damman K, Van der Meer P, Voors AA, et al. Clinical and hemodynamic correlates and prognostic value of VE/VCO2 slope in patients with heart failure with preserved ejection fraction and pulmonary hypertension. J Card Fail. 2017;23(11):777-82.

19. Canada JM, Trankle CR, Buckley LF, Carbone S, Abouzaki NA, Kadariya D, et al. Severely impaired cardiorespiratory fitness in patients with recently decompensated systolic heart failure. Am J Cardiol. 2017;120(10):1854-7.

20. Shen Y, Zhang X, Ma W, Song H, Gong Z, Wang $\mathrm{Q}$, et al. VE/VCO2 slope and its prognostic value in patients with chronic heart failure. Exp Ther Med. 2015;9(4):1407-12.

21. Shafiek H, Valera JL, Togores B, Torrecilla JA, Sauleda J, Cosío BG. Risk of postoperative complications in chronic obstructive lung diseases patients considered fitfor lung cancer surgery: beyond oxygen consumption. Eur J Cardiothorac Surg. 2016;50(4):772-9.

22. Nusair S. Interpreting the incremental cardiopulmonary exercise test. Am J Cardiol. 2017;119(3):497-500. 
23. Ramos PS, Araújo CG. Cardiorespiratory optimal point during exercise testing as a predictor of allcause mortality. Rev Port Cardiol. 2017;36(4):261-9.

24. Laethem CV, de Sutter J, Peersman W, Calders P. Intratest reliability and test-retest reproducibility of the oxygen uptake efficiency slope in healthy participants. Eur J Cardiovasc Prev Rehabil. 2009;16:493-8.
25. Dougherty RJ, Lindheimer JB, Stegner AJ, Van Riper S, Okonkwo OC, Cook DB. An Objective method to accurately measure cardiorespiratory fitness in older adults who cannot satisfy widely used oxygen consumption criteria. J Alzheimers Dis. 2018;61(2):601-11. 